\title{
Reproduction parthénogénétique de Moina macrocopa (Straus 1820) (Crustacea : Cladocera). Influence des conditions trophiques, de la densité de population, du groupement et de la température
}
A. Benider 1
A. Tifnouti ${ }^{1}$
R. Pourriot ${ }^{2}$

Mots-clés : Cladocère, lagunage, Moina macrocopa, reproduction.

La fécondité et le développement de Moina macrocopa, seul Cladocère des bassins de lagunage de Marrakech, ont été étudiés au laboratoire à 7 concentrations en algues et à 5 températures différentes. L'effet de la densité de population et du groupement a été également testé.

Les conditions de carence alimentaire sont une des principales causes de la réduction de la fécondité de $M$. macrocopa. Nous avons montré qu'un apport insuffisant de nourriture correspondant à une concentration en algues inférieure à $3,125.10^{4}$ cellules/ml, supprimait tout phénomène de reproduction. En revanche, l'accroissement du niveau des ressources, au delà de cette concentration seuil de reproduction, était à l'origine d'une amélioration de la fécondité chez $M$. macrocopa qui se traduit par une augmentation du nombre de portées suivie par l'augmentation du nombre de jeunes par portées.

Les expériences réalisées ont permis également de démontrer l'influence néfaste d'un accroissement de la densité de population sur la fécondité de $M$. macrocopa. Cependant, aucun effet de groupement sur les processus de reproduction n'a été mis en évidence chez cette espèce.

Parthenogenetic reproduction of Moina macrocopa (Straus 1820) (Crustacea : Cladocera) : trophic conditions, population density, grouping and temperature influence

Keywords : Cladocera, lagunage, Moina macrocopa, reproduction.

The fecundity and development of Moina macrocopa, the only cladoceran living in the waste water sedimentation ponds of Marrakech, have been studied in the laboratory at seven varying algal concentrations and at five different temperatures. Population density and grouping effects were also investigated.

The conditions of food deficiency are one of the major cause of the reduced fecundity in Moina macrocopa. We showed, that an insufficient food supply corresponding to an algae concentration lower than $3.125 .10^{4} \mathrm{cells} / \mathrm{ml}$, would suppress (remove) any reproductive phenomenon. In contrast, the increase of resource level beyond this reproductive concentration threshold, allowed fecundity of Moina macrocopa to improve which appears as an increase in the brood number (frequency) rather than an increase of the brood size.

The experiments also allowed us to show the harmful effect of an increase of population density on the fecundity of $M$. $m a$ crocopa. However, no grouping effect on reproductive processes has been observed in this species.

\section{Introduction}

Dans les bassins expérimentaux de lagunage de Marrakech, un seul Cladocère Moina macrocopa (Straus 1820) a été rencontré. Dans ces travaux, l'accent est mis sur deux faits marquants :

1. Laboratoire d'Hydrobiologie, Département de Biologie. Faculté des Sciences Semlalia, Universite Cadi Ayyad. B.P. S 15. 40000 Marrakech, Maroc.

2. Laboratoire de Géologie Appliquée, B123, Université Paris 6, Place Jussieu, F - 75252 Paris Cedex, France.
- la disparition subite de cette espèce un mois et demi seulement après son apparition,

- l'absence d'une espèce de Daphnidae (Daphnia magna), dominant le plus souvent les populations de Cladocères dans d'autres bassins d'épuration (Loedolf 1965, Angeli 1979, Pizay-Parenty 1985), et qui pourtant est présente dans différents milieux aquatiques proches de la zone d'épandage des eaux usées de Marrakech (Tifnouti et al. 1984).

Dans leur analyse, les auteurs (Loedolf 1965, de Dinges 1973, Angeli 1979) attribuent ces phénomènes à la qualité des eaux. Ils évoquent également l'existen- 
ce possible d'une compétition interspécifique entre Moina et Daphnia, qui dépendrait d'une stratégie démographique spécifique et du niveau des ressources.

Les différents travaux réalisés sur les Moïnidae ont trait à l'influence des conditions environnementales, principalement la température, sur la reproduction parthénogénétique (Murugan 1975, Magadza 1977, Vijverberg 1980, Hanazato \& Yasuno 1984, 1985, Mangalo \& Akbar 1986, Gordo \& Canavate 1989, Lazim \& Faisal 1989, Bonou et al. 1991, Gordo et al. 1994).

Cette étude représente donc un maillon supplémentaire, et devrait contribuer à la compréhension des effets du niveau des ressources, des conditions thermiques, de la densité de population et du groupement sur la dynamique de population de cette espèce.

\section{Matériel et méthodes}

\section{- Souche de Moina macrocopa}

La souche utilisée dans ce travail est issue de l'éclosion d'une seule éphippie récoltée le 19 janvier 1989 dans les sédiments du deuxième bassin de lagunage de Marrakech (Benider 1991). Cette souche s'est reproduite ensuite de manière parthénogénétique pendant toute la durée des expériences (environ 20 mois) sans montrer aucun signe de dégénérescence. Dans le but d'éliminer l'effet éventuel de l'âge des parents sur la croissance et la reproduction des descendants (à l'image de certaines espèces de Rotifères, cf. Pourriot \& Rougier 1976), les femelles utilisées dans toutes les expériences correspondent à la première génération.

\section{- Cultures d'algues}

Comme nourriture pour les élevages (Tableau 1), nous avons utilisé des cultures de Chlorella sorokiniana, microalgue appartenant à l'ordre des Chlorococcales et signalée à maintes reprises dans les bassins de lagunage de Marrakech (Chifâa 1987).

Les cellules de $C$. sorokiniana ont un diamètre moyen de $3 \mu \mathrm{m}$ et un biovolume de $14 \mu \mathrm{m}^{3}$. Le poids frais par cellule est estimé à $14.10^{-6} \mu \mathrm{g}$.

\section{- Milieu d'élevage}

Nous avons utilisé pour nos élevages une eau de source, dénommée Sidi Ali, diluée par moitié avec de l'eau bidistillée (Benider 1991). La teneur totale en ions minéraux est de l'ordre de $100 \mathrm{mg} / 1$, avec une dominance de bicarbonates et une faible dureté.

\section{- Protocole expérimental}

Les méthodes appliquées pour déterminer la durée des stades de développement s'inspirent des travaux de Gras \& St-Jean (1978b, 1981a).
Les femelles sont entretenues séparément dans des cristallisoirs en verre (diamètre : $3,8 \mathrm{~cm}$, hauteur : 2,5 $\mathrm{cm}$ ) contenant $15 \mathrm{ml}$ du milieu d'élevage et $1 \mathrm{ml}$ d'une suspension de Chlorelles ( $10^{7}$ cellules/ml); la concentration en algues du milieu d'élevage est alors de $6,25.10^{5}$ cellules $/ \mathrm{ml}$. Les cristallisoirs sont recouverts à l'aide d'un verre de montre et placés dans un bain thermostaté à $25^{\circ} \mathrm{C}$ et à l'obscurité.

L'effet de la densité de population et du groupement a été étudié en effectuant 3 séries d'expériences :

- lot «témoin» (T) : 1 femelle/16 ml

- lot «densité» (D) : 1 femelle/5,34 ml

- lot «groupement» $(\mathrm{G}): 3$ femelles $/ 48 \mathrm{ml}$

Pour étudier l'influence des conditions trophiques sur la reproduction des Moina, 15 à 36 nouveaux-nés sont placés dans les conditions d'élevage précitées, avec des concentrations en algues du milieu d'élevage comprises entre 6,25 et $6,25.10^{5}$ cellules/ml (Tableau 1) (Benider 1991). Pour déterminer l'effet de la température sur le développement et la fécondité des Moina, les expériences sont effectuées dans des bains thermostatés, de 10 à $35^{\circ} \mathrm{C}$, avec une concentration en algues du milieu d'élevage de $6,25 \cdot 10^{5}$. cellules $/ \mathrm{ml}$. Les observations sont espacées de 4 heures.

Les Moina sont acclimatées aux conditions à tester. Afin d'étudier l'impact du niveau des ressources sur la durée du développement embryonnaire (De) et juvénile (Dp), ainsi que sur le temps de génération $(\mathrm{Tg})$, nous avons réalisé une série d'expériences à $25^{\circ} \mathrm{C}$ avec un nombre de femelles compris entre 14 et 29 femelles correspondant toutes à la génération F1. Pour chaque concentration en algues du milieu d'élevage, des observations ponctuelles ont été effectuées à des intervalles de temps de 4 heures; ces mesures rapprochées permettent d'avoir une meilleure précision que celles obtenues avec des observations réalisées toutes les 24 heures.

- Expression des résultats et traitements des données

Pour chaque expérience, différents paramètres sont déterminés :

- la durée de développement embryonnaire (De), temps séparant la ponte des oeufs de leur éclosion ;

- la durée du développement post-embryonnaire (Dp) ou juvénile, intervalle entre la naissance et la première ponte ;

- le nombre de femelles ovigères ;

- le nombre de jeunes par femelle ovigère ;

- le nombre moyen de portées par femelle ;

- le nombre moyen d'oeufs par portée ;

- le taux de mortalité. 
Tableau 1. Concentrations en algues expérimentées.

Table 1. Tested algal concentrations.

\begin{tabular}{ccl}
\hline $\begin{array}{c}\text { Concentration de la culture } \\
\text { d'algues (cellules } / \mathrm{ml} \text { ) }\end{array}$ & $\begin{array}{l}\text { Concentration en algues du } \\
\text { milieu d' élevage (cellules/ml) }\end{array}$ & Abréviation \\
\hline $10^{2}$ & 6,25 & $\mathrm{C} 0$ \\
$10^{4}$ & 625 & $\mathrm{C} 2$ \\
$10^{5}$ & 6250 & $\mathrm{C} 3$ \\
$2,5.10^{5}$ & 15625 & $\mathrm{C} 3_{(2.5)}$ \\
$5.10^{5}$ & 31250 & $\mathrm{C} 3_{(5)}$ \\
$10^{6}$ & 62500 & $\mathrm{C} 4$ \\
$10^{7}$ & 625000 & $\mathrm{C5}$ \\
\end{tabular}

\section{Résultats}

\subsection{Influence des conditions trophiques}

Aux faibles concentrations en algues du milieu d'élevage (inférieures à la concentration C3 (5) aucune reproduction n'est observée. Les résultats présentés concernent donc les données obtenues avec des apports alimentaires correspondant aux concentrations C3 (5), C4 et C5.

3.1.1. Effet des conditions nutritionnelles sur le développement de M. macrocopa

La durée du développement embryonnaire augmente avec la diminution de la concentration en algues du milieu d'élevage; les valeurs enregistrées varient entre 26 et 44 heures (Tableau 2). Ces résultats semblent confirmer l'existence d'une relation entre la femelle parentale et les embryons qu'elle porte. Goulden (1968) signale la présence, chez les Moinidae, d'une sorte de placenta (appelé «Nährboden» par Weismann 1877, in Goulden 1968) par l'intermédiaire duquel la femelle fournit à l'embryon une partie des éléments nutritifs nécessaires à son développement.

Comparée à d'autres espèces de Moinidae, $M$. macrocopa a, dans des conditions trophiques suffisantes et pour une même température $\left(25^{\circ} \mathrm{C}\right)$, une durée de développement embryonnaire voisine de celles signalées chez Moina micrura (33 heures : Gras \& St-Jean 1976; 30 heures : Hanazato \& Yasuno 1985), Moina brachiata (28 heures : Hart 1985), Moina dubia (18 heures : Magadza 1977) et Moina micrura (27 heures : Bonou et al. 1991).

Au terme du développement des embryons, les jeunes éclosent et croissent ensuite pour atteindre la maturité sexuelle. Les résultats obtenus montrent un accroissement considérable de la durée du développement juvénile lorsque la concentration en algues du milieu d'élevage diminue de C4 à C3(5) (Tableau 2). Cet effet est par ailleurs plus prononcé que celui observé sur De (le rapport $\mathrm{Dp} / \mathrm{De}$ passant du simple au double entre $\mathrm{C} 4$ et $\mathrm{C} 3(5)$. Aux concentrations plus élevées (C4

Tableau 2. Durée du développement embryonnaire (De), post-embryonnaire (Dp), et temps minimum de génération ( $\mathrm{Tg}$ ) en fonction de la concentration des algues du milieu d'élevage (température $=25^{\circ} \mathrm{C}$ ). Les chiffres entre parenthèses indiquent le nombre de femelles utilisées.

Table 2. Embryonic (De), post embryonic (Dp) and minimal generation time ( $\mathrm{Tg}$ ) as a function of algae concentration in culture medium (temperature $=25^{\circ} \mathrm{C}$ ). The number of tested females is indicated in bracklets.

\begin{tabular}{lcccc}
\hline $\begin{array}{c}\text { Concentrations en algues } \\
\text { (cellules/ml) }\end{array}$ & $\begin{array}{c}\text { De } \\
\text { (heures) }\end{array}$ & $\begin{array}{c}\mathrm{Dp} \\
\text { (heures) }\end{array}$ & $\begin{array}{c}\mathrm{Tg} \\
\text { (heures) }\end{array}$ & $\mathrm{Dp} / \mathrm{De}$ \\
\hline $3,125 \cdot 10^{4}=\mathrm{C}_{(5)}$ & $44 \pm 16$ & $138 \pm 54$ & $182 \pm 54$ & $(29)$ \\
& $(29)$ & $(29)$ & $81 \pm 7$ & 3,1 \\
$6,25 \cdot 10^{4}=\mathrm{C} 4$ & $31 \pm 6$ & $49 \pm 6$ & $(16)$ & 1,6 \\
& $(16)$ & $(16)$ & $71 \pm 5$ & \\
$6,25 \cdot 10^{5}=\mathrm{C} 5$ & $26 \pm 5$ & $45 \pm 2$ & $(14)$ & 1,7 \\
& $(14)$ & $(14)$ & & \\
\hline
\end{tabular}


et C5), les différences notées ne sont plus significatives; les valeurs de Dp obtenues (45 et 49 heures) sont du même ordre de grandeur que celles signalées chez Moina micrura ( 40 heures à $25^{\circ} \mathrm{C}$ : Gras \& St-Jean 1976; 42 heures à $25^{\circ} \mathrm{C}$ : Hanazato \& Yasuno 1985 ).

L'évolution du temps de génération ( $\mathrm{Tg}$ ), intervalle de temps minimum séparant deux générations successives, pour les 3 concentrations en algues considérées est identique à celle des deux paramètres précédents (Tg étant égal à De+Dp). Ce temps varie de 182 à 71 heures. Cette dernière valeur est toutefois proche des données de la littérature : 72 heures à $25^{\circ} \mathrm{C}$ chez $\mathrm{Moi}$ na micrura (Hanazato \& Yasuno 1985).

L'évolution de $1 / \mathrm{De}, 1 / \mathrm{Dp}$ et $1 / \mathrm{Tg}$, pour les 3 concentrations en algues est similaire. On observe une augmentation rapide de ces paramètres entre les concentrations $\mathrm{C} 3(5)$ et $\mathrm{C} 5$, reflétant le passage des conditions nutritionnelles limites $(\mathrm{C} 3(5))$ à un niveau trophique suffisant (C5).

\subsubsection{Evolution de la fécondité de M. macrocopa avec la concentration en algues}

L'évolution globale des paramètres relatifs à la fécondité (Nombre total moyen de jeunes par femelle, nombre moyen de portées par femelle et nombre moyen de jeunes par portée) en fonction des 3 concentrations en algues considérées (Fig. 1) nous a permis, consécutivement à l'amélioration du niveau trophique, de mettre en évidence les caractéristiques suivantes :

- augmentation particulièrement nette du nombre total moyen de jeunes par femelle; les valeurs moyennes obtenues sont respectivement de $3 \pm 2$ (à C3(5)), $17 \pm$ 6 (à C4) et $68 \pm 23$ (à C5) jeunes/femelle (Fig. 1A) ;

- accroissement du nombre moyen de portées par femelle; les résultats enregistrés s'échelonnent entre 1,7 $\pm 1,1$ (à C3(5)) et 5,5 $\pm 1,5$ (à C5) portées/femelle (Fig. 1B). Il faut signaler cependant que la différence observée, entre les niveaux trophiques $\mathrm{C} 4$ et C5, n'est pas significative ;

- augmentation du nombre moyen de jeunes par portée qui varie entre $1,6 \pm 0,9$ (C3(5)) et $12,2 \pm 1,4$ (C5) jeunes/portée (Fig. 1C). Les différences observées sont toutes significatives au seuil de probabilité de $5 \%$.

Pour ces 3 paramètres de fécondité, des variations individuelles peuvent être observées.

A partir de ces données globales, nous avons représenté les variations du nombre moyen de jeunes en fonction du nombre moyen de portée (Fig. 2). L'analyse de cette figure indique qu'aux concentrations C3(5) et $\mathrm{C} 4$ la 1ère portée est la plus productive; les valeurs

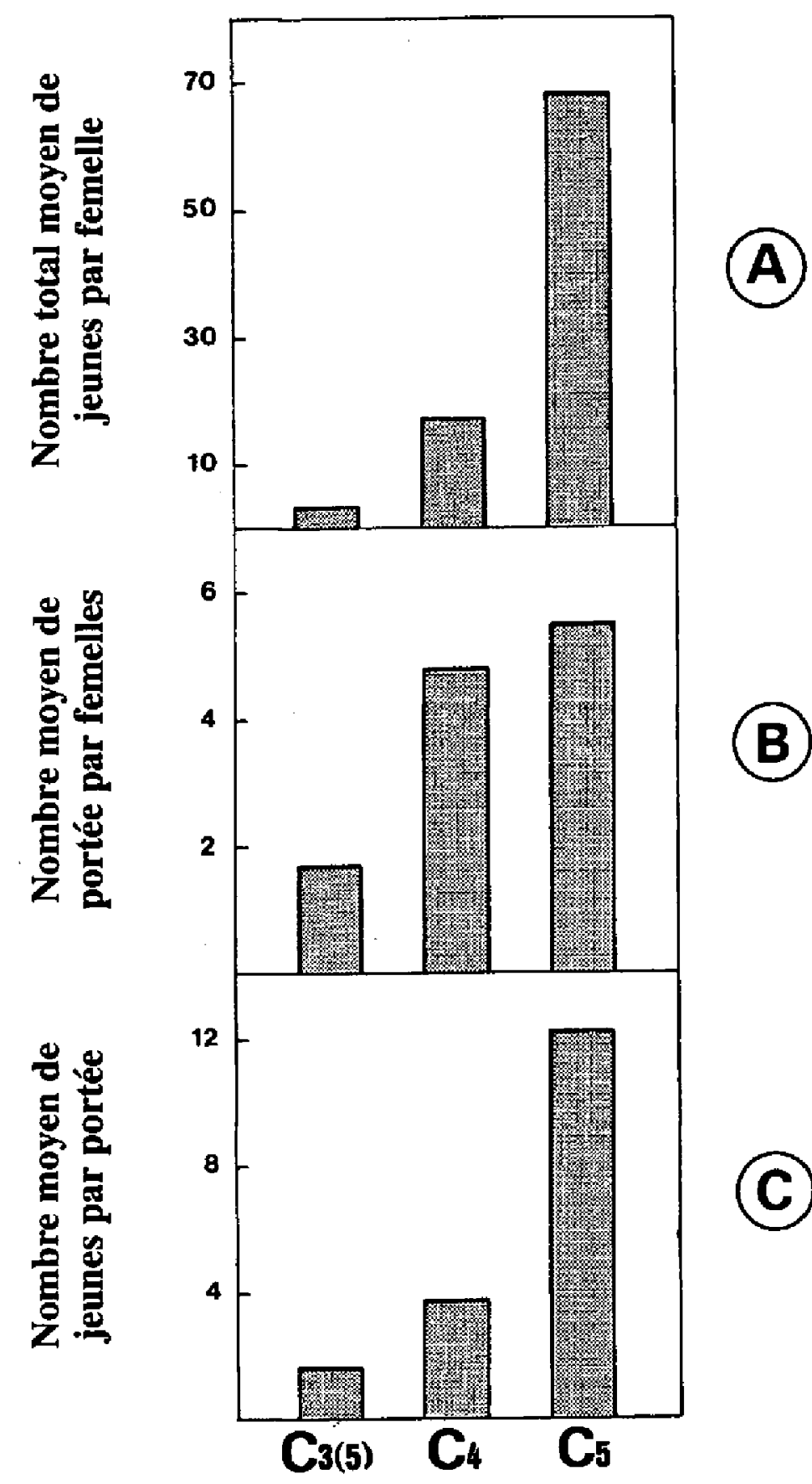

Concentration en algues (cellules/ml)

Fig. 1. Nombre total moyen de jeunes par femelle (A), nombre moyen de portées par femelle (B) et nombre moyen de jeunes par portée (C) chez $M$. macrocopa, à 3 concentrations en algues (température : $25^{\circ} \mathrm{C} . \mathrm{C}_{3(5)}$ à $\mathrm{C}_{5}$ : Tableau 1.

Fig. 1. Total reproductive output (A), brood number per female (B) and the average brood size (C) in Moina macrocopa, at 3 algae concentrations (temperature : $25^{\circ} \mathrm{C}$ ). $\mathrm{C}_{3(5)}$ in $\mathrm{C}_{5}$ : Table 1 .

calculées étant respectivement de 1,7 et 5,5 jeunes. Par la suite, la taille des portées diminue pour atteindre des valeurs très faibles de l'ordre de 0,1 à 0,4 jeune.

L'ensemble de ces résultats démontre de manière explicite l'influence des conditions trophiques sur la fécondité chez $M$. macrocopa. Les différents paramètres 
mesurés atteignent des valeurs optimales pour des concentrations en algues relativement élevées $\left(=6,25 \cdot 10^{5} \mathrm{cell} . / \mathrm{ml}\right)$. Ces observations rejoignent certaines données recueillies «in situ» par Tifnouti et al. (1989) avec une augmentation du nombre de jeunes par portée (de 6 à 21) consécutive à un accroissement du niveau des ressources (de 7,5.104 à $10^{6}$ cell. $/ \mathrm{ml}$ ). Par ailleurs, Hanazato \& Yasuno (1984) rapportent une fécondité de 116 jeunes par femelle chez $M$. macrocopa nourrie de Chlorella sp. à la concentration de $10^{6}$ cell./ml et maintenue à une température de $23^{\circ} \mathrm{C}$ et sous une photopériode $\mathrm{LD}=16: 8$. Dans les mêmes conditions, ces auteurs obtiennent une production maximale de 35 jeunes à la 3 ème portée. Pour deux types d'algues (Chlorella et Microcystis), ces auteurs ont montré l'importance de la qualité de la nourriture sur la fécondité de $M$. macrocopa. D'une manière générale, l'existence d'un lien étroit entre la fécondité et le niveau des ressources disponibles fait que la taille des portées pourrait servir d'indicateur des conditions trophiques du milieu. Parallèlement, notre étude sur la fécondité met en évidence l'existence d'une concentration seuil de reproduction. Celle-ci correspond à un apport de $3,125.10^{4} \mathrm{cell} . / \mathrm{ml}$ de milieu d'élevage (=C3(5)) ou encore de $0,13 \mathrm{mg}$ de poids sec/litre (une cellule de chlorelle à un poids frais moyen d'environ $14.10^{-6} \mu \mathrm{g}$ et le poids sec représente environ $30 \% \mathrm{du}$

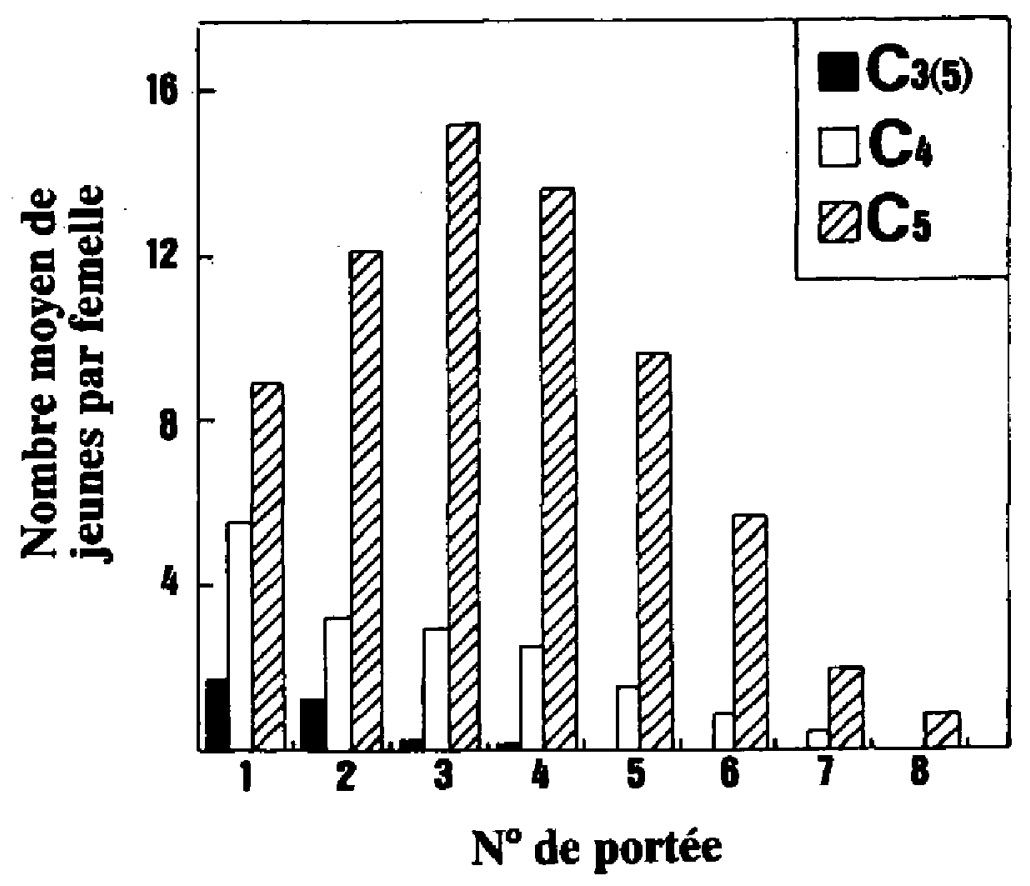

Fig. 2. Nombre moyen de jeunes par femelle en fonction de l'ordre des portées, à 3 concentrations en algues (température : $25^{\circ} \mathrm{C}$. $\mathrm{C}_{3(5)}$ à $\mathrm{C}_{5}^{\prime}$ : Tableau 1.

Fig. 2. Mean number of the brood size according to the order at algal concentrations (temperature : $25^{\circ} \mathrm{C}$ ). $\mathrm{C}_{3(5)}$ in $\mathrm{C}_{5}$ : Table 1. poids frais). Chez Moina micrura (Duncan 1989), la concentration seuil varie entre 0,06 et $0,2 \mathrm{mg}$ de poids $\mathrm{sec/litre} \mathrm{selon} \mathrm{la} \mathrm{température} \mathrm{utilisée} \mathrm{pour} \mathrm{son} \mathrm{élevage.}$

\subsection{Influence de la densité de population et du groupement}

Les résultats sont assez similaires (Fig. 3). On observe dans un premier temps une augmentation de la production journalière de jeunes, avec un maximum de 10 à 12 jeunes/femelle au $5^{\text {ème }}$ ou 6 ème jour. Par la suite, la fécondité journalière diminue progressivement avec l'âge de la mère.

L'absence d'un effet de la densité de population sur ce dernier paramètre montre donc que la diminution de la fécondité totale par femelle observée à la densité de population de 1 femelle $/ 5,34 \mathrm{ml}$ est une conséquence de la réduction du nombre moyen de portées par femelle. Ces observations se recoupent avec celles de Moina micrura dont les densités de population très élevées (> à 1700 ind/l) entraînent un arrêt total de la reproduction des individus alors que le niveau des ressources est encore suffisant (Jana \& Pal 1985b).

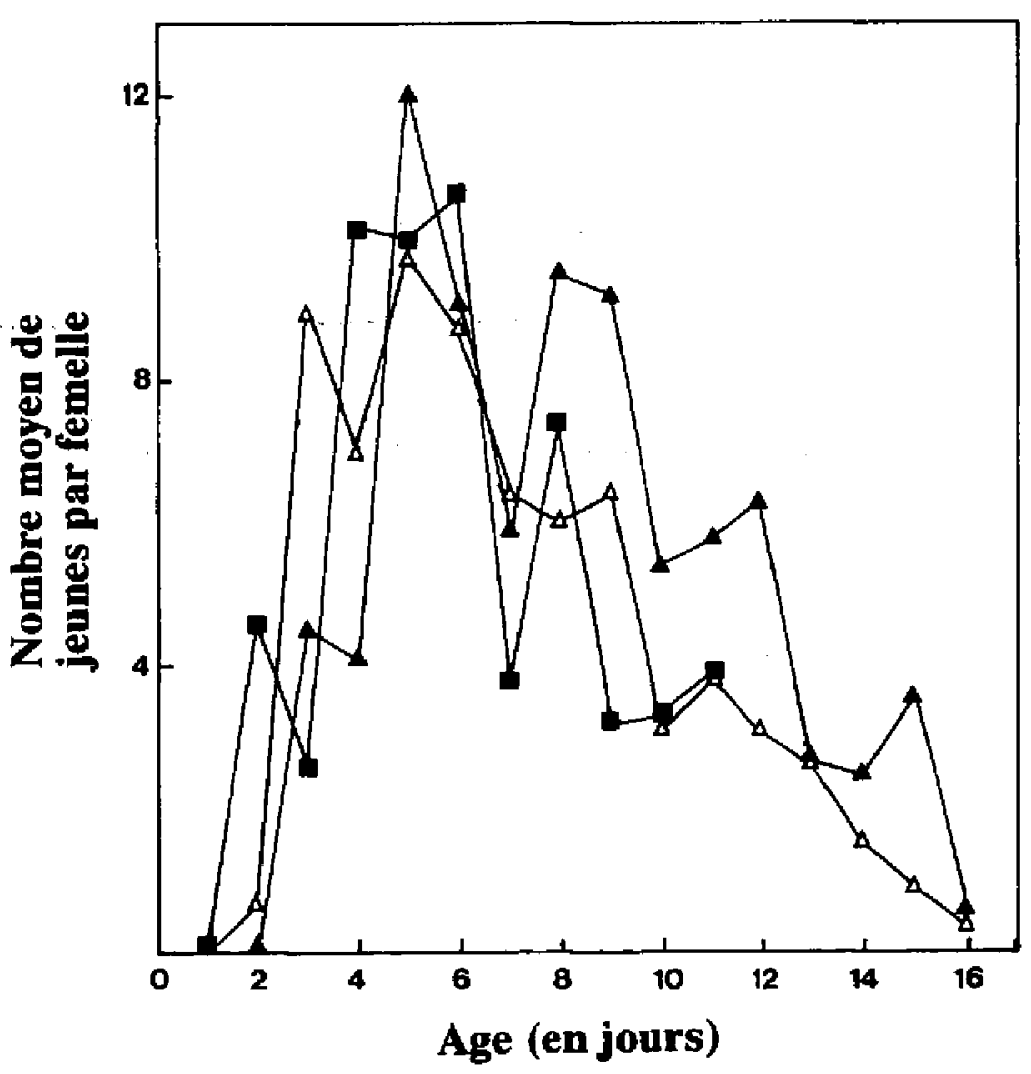

Fig. 3. Evolution de la fécondité avec l'âge de la mère, en fonction de la densité de population $(D=G)$ et du groupement $(G=\Delta)$ par rapport à un témoin $(\mathrm{T}=\boldsymbol{\Lambda})$.

Fig. 3. Changes in fecundity with the age of carrier females according to population density $(D=\square)$ and grouping $(G=\Delta)$ effect compared to a control $(\mathrm{T}=\mathbf{A})$. 


\subsection{Influence de la température}

\subsubsection{Action de la température sur le développement de $M$. macrocopa}

Les résultats obtenus montrent que la durée de développement embryonnaire (De) est d'autant plus longue que la température d'élevage est faible (Tableau 3).

La durée de développement post-embryonnaire (Dp) est également sous la dépendance du facteur thermique. La réduction de la durée de développement post-embryonnaire, engendrée par des températures d'élevage élevées, correspond à la diminution du nombre de stades juvéniles et de leur durée. D'autre part, les variations du temps de génération $(\mathrm{Tg})$ avec la température vont dans le même sens que celles de De et $\mathrm{Dp}$ aux températures utilisées $\left(15\right.$ à $\left.30^{\circ} \mathrm{C}\right)$.

Des résultats évoluant dans le même sens ont été décrits par Gras \& St-Jean (1978b) sur Moina micrura. Ils soulignent que la température est le principal facteur agissant sur la durée de développement embryonnaire et post-embryonnaire. Ils montrent que les variations de la durée de développement juvénile met en jeu deux mécanismes, la modification du nombre moyen de stades et celle de leur durée. Des travaux antérieurs (Brown 1929), soulignaient déjà l'influence de la température sur le temps de génération.
Chez d'autres espèces du genre Moina, les différentes études réalisées montrent que les temps de développement $(\mathrm{De}, \mathrm{Dp}$ et $\mathrm{Tg})$ sont similaires à ceux de $M$. macrocopa, et indiquent également un développement embryonnaire et juvénile plus rapide aux températures voisines de 25 et $30^{\circ} \mathrm{C}$ (Tableau 4). Les variations interspécifiques observées pourraient cependant têtre liées à des différences génétiques, aux conditions d'élevage (nature du milieu, qualité et quantité de nourriture, photopériode, etc...), ou encore à la méthode d'étude utilisée (fréquence des observations notamment).

La courbe représentant l'évolution du taux de développement embryonnaire (1/De) a une allure sigmoïde; la pente est plus forte entre 18 et $25^{\circ} \mathrm{C}$ qu'entre 15 et $18^{\circ} \mathrm{C}$ d'une part et 25 et $30^{\circ} \mathrm{C}$ d'autre part. Chez $M$. macrocopa, la zone optimale du développement embryonnaire se situerait donc approximativement entre 20 et $25^{\circ} \mathrm{C}$ (Fig. 4 ).

Dans le cas du taux de développement juvénile $(1 / \mathrm{Dp})$, on observe une rupture de pente à $18^{\circ} \mathrm{C}$; celleci revient à sa valeur initiale à partir de $20^{\circ} \mathrm{C}$ (Fig. 4).

Les variations de $1 / \mathrm{Tg}$ correspondent à une fonction sensiblement linéaire, dans l'intervalle de température testé $\left(15\right.$ à $\left.30^{\circ} \mathrm{C}\right)$ (Fig. 4).

Tableau 3. Durée du développement embryonnaire (De), post-embryonnaire (Dp), et temps minimum de génération (Tg) en fonction de la température (concentration en algues $=6.25 .10^{5}$ cellules $/ \mathrm{ml}$ ). Les chiffres entre parenthèses indiquent le nombre de femelles utilisées.

Table 3. Embryonic, post embryonic and minimal generation time $(\mathrm{Tg})$ as a function of temperature (algae concentration $=6.25 .10^{5} \mathrm{cells} / \mathrm{ml}$ ).

\begin{tabular}{|c|c|c|c|c|}
\hline $\begin{array}{l}\text { Température } \\
\left({ }^{\circ} \mathrm{C}\right)\end{array}$ & $\begin{array}{c}\mathrm{De} \\
\text { (heure) }\end{array}$ & $\begin{array}{c}\mathrm{Dp} \\
\text { (heure) }\end{array}$ & $\begin{array}{l}\mathrm{Tg} \\
\text { (heure) }\end{array}$ & $\mathrm{Dp} / \mathrm{De}$ \\
\hline 15 & $\begin{array}{l}129 \pm 10 \\
(14)\end{array}$ & $\begin{array}{c}183 \pm 12 \\
(14)\end{array}$ & $\begin{array}{c}312 \pm 7 \\
(14)\end{array}$ & 1,4 \\
\hline 18 & $\begin{array}{c}79 \pm 11 \\
(14)\end{array}$ & $\begin{array}{c}120 \pm 0 \\
(14)\end{array}$ & $\begin{array}{c}199 \pm 11 \\
(14)\end{array}$ & 1,5 \\
\hline 20 & $\begin{array}{c}46 \pm 4 \\
(16)\end{array}$ & $65 \pm 8$ & $\begin{array}{c}122 \pm 7 \\
(16)\end{array}$ & 1,4 \\
\hline 25 & $\begin{array}{c}26 \pm 5 \\
(14)\end{array}$ & $\begin{array}{r}45 \pm 2 \\
(14)\end{array}$ & $\begin{array}{c}71 \pm 5 \\
(14)\end{array}$ & 1,7 \\
\hline 30 & $\begin{array}{r}25 \pm 4 \\
(13)\end{array}$ & $\begin{array}{r}32 \pm 4 \\
(13)\end{array}$ & $\begin{array}{r}57 \pm 1 \\
(13)\end{array}$ & 1,3 \\
\hline
\end{tabular}


Tableau 4. Durée du développement embryonnaire (De), post-embryonnaire (Dp), et temps minimum de génération (Tg) de trois espèces de Moinidae. (1) : Brown (1929) - (2) : présent travail - (3) : Hanazato \& Yasuno (1985) - (4) : Murugan (1975) - (5) : Gras \& Saint-Jean (1978b) (6) : Hart (1985) - (7) : Gauthier (1954) - (8) : Bonou et al (1991).

Table 4. Embryonic and post embryonic development lengths $(\mathrm{De})$, and minimal generation time ( $\mathrm{Tg}$ ) of 3 Moinidae species.

\begin{tabular}{|c|c|c|c|c|c|c|c|c|c|c|c|c|c|}
\hline \multirow[b]{2}{*}{$\begin{array}{c}\text { Température } \\
\left({ }^{\circ} \mathrm{C}\right)\end{array}$} & \multicolumn{4}{|c|}{ De (heures) } & \multicolumn{4}{|c|}{ Dp (heures) } & \multicolumn{4}{|c|}{ Tg (heures) } & \multirow[b]{2}{*}{ Réf. } \\
\hline & 15 & 20 & 25 & 30 & 15 & 20 & 25 & 30 & 15 & 20 & 25 & 30 & \\
\hline H. macrocopa & 129 & 46 & 26 & 25 & 183 & 65 & 45 & 32 & 312 & $\begin{array}{l}112 \\
114\end{array}$ & $\begin{array}{l}71 \\
67\end{array}$ & $\begin{array}{l}57 \\
49\end{array}$ & $\begin{array}{l}(1) \\
(2)\end{array}$ \\
\hline M. micrura & 120 & $\begin{array}{l}66 \\
56 \\
62\end{array}$ & $\begin{array}{l}30 \\
30 \\
33 \\
29^{*}\end{array}$ & $\begin{array}{l}24 \\
24 \\
23 \\
20\end{array}$ & $\begin{array}{l}144 \\
108\end{array}$ & $\begin{array}{l}54 \\
54\end{array}$ & $\begin{array}{l}42 \\
26 \\
38 \\
33\end{array}$ & $\begin{array}{l}24 \\
26 \\
22 \\
19\end{array}$ & 264 & $\begin{array}{l}120 \\
110\end{array}$ & $\begin{array}{l}72 \\
56 \\
71 \\
62\end{array}$ & $\begin{array}{l}48 \\
50 \\
45 \\
39 \\
48\end{array}$ & $\begin{array}{l}(3) \\
(4) \\
(5) \\
(6) \\
(7)\end{array}$ \\
\hline M. brachiata & & 72 & $\begin{array}{l}28 \\
28\end{array}$ & $\begin{array}{l}23 \\
21\end{array}$ & 111 & 72 & & & & 144 & & & $\begin{array}{l}(4) \\
(8)\end{array}$ \\
\hline
\end{tabular}

Par ailleurs, les observations effectuées chez $M . m a-$ crocopa montrent que le rapport $\mathrm{Dp} / \mathrm{De}$ est indépendant de la température. Cette caractéristique n'est pas propre à $M$. macrocopa ; Gras \& St-Jean (1978b) signalent également un rapport constant de l'ordre de 1,23 entre 25 et $30^{\circ} \mathrm{C}$ chez Moina micrura. De même, Kryuchkova (1973 in Gras \& St-Jean (1978b) indique une valeur égale à 1,5 chez Moina brachiata, dans l'intervalle $22-23^{\circ} \mathrm{C}$.

Ces quelques données concernant les Moina suggèrent que la rapidité du développement est une caractéristique du genre, voire de la famille des Moinidae. Cette évolution témoigne de l'adaptation de $M$. macrocopa aux températures élevées. En effet, $M$. macrocopa a pu être observée dans les bassins de lagunage de Marrakech à des températures variant de 18 à $26^{\circ} \mathrm{C}$ (Tifnouti et al. 1989). Le taux de développement postembryonnaire, n'est très apparent qu'entre 15 et $20^{\circ} \mathrm{C}$.

3.3.2. Variations de la fécondité de M. macrocopa avec la température

L'évolution de la fécondité journalière en fonction de l'âge de la mère, pour les différentes températures étudiées montre l'existence $\mathrm{d}^{t} u n e$ rythmicité apparente au niveau de la production journalière de jeunes, plus particulièrement aux températures de 15,18 et $20^{\circ} \mathrm{C}$. Lorsque la température d'élevage est plus élevée $\left(25\right.$ et $30^{\circ} \mathrm{C}$ ), cette rythmicité est beaucoup moins marquée $\left.25^{\circ} \mathrm{C}\right)$, voire même absente $\left(30^{\circ} \mathrm{C}\right)$.

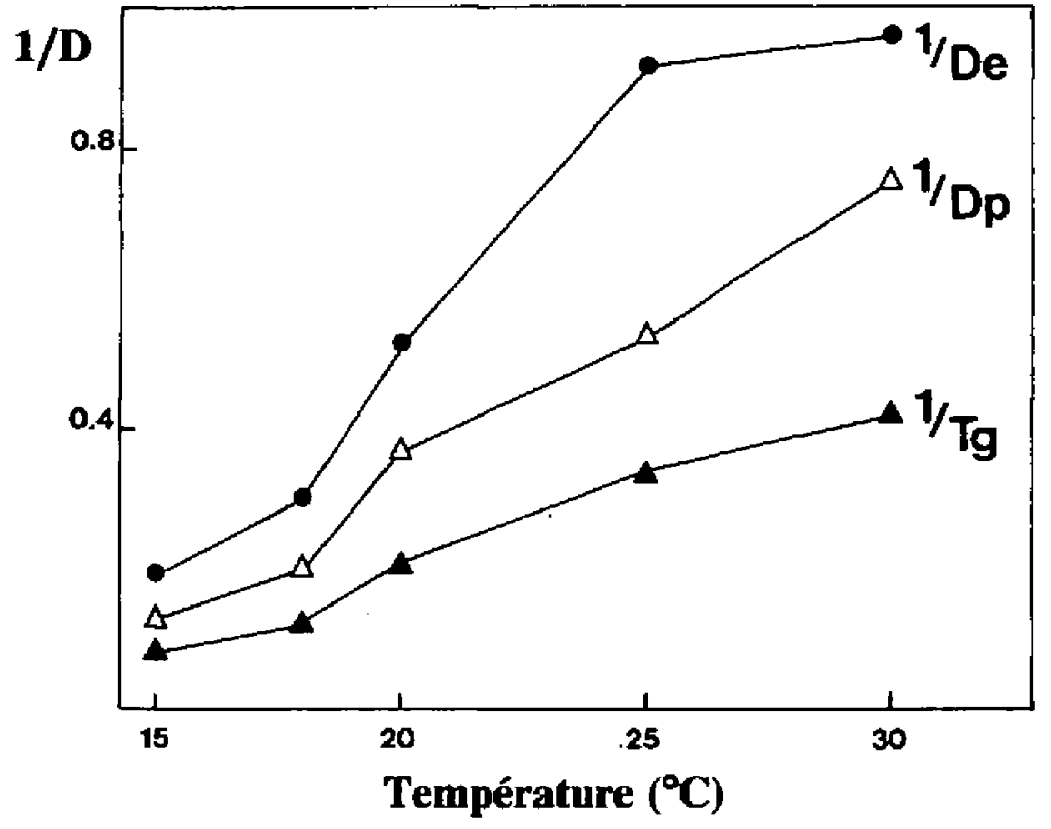

Fig.4. Variation de $1 / \mathrm{De}, 1 / \mathrm{Dp}$ et $1 / \mathrm{Tg}$ en fonction de la température (concentration en algues : $6,25.10^{5}$ cellules $/ \mathrm{ml}$ ).

Fig. 4. Variation of $1 / \mathrm{De}, 1 / \mathrm{Dp}$ and $1 / \mathrm{Tg}$ with the temperature (algal concentration : $6,25 \cdot 10^{5}$ cells $/ \mathrm{ml}$ ).

Par ailleurs, on constate un décalage dans le temps des maxima de fécondité journalière avec la diminution de la température (Fig. 5). Les observations effectuées mettent également en évidence une fécondité maximale journalière supérieure aux températures élevées; le maximum enregistré à $15^{\circ} \mathrm{C}$ étant de 4 jeunes 
seulement au $13^{\text {ème jour alors que celui-ci atteint à }}$ $30^{\circ} \mathrm{C}$ la valeur de 15 jeunes au 4 ème jour.

Pour compléter l'étude de la reproduction de $M$. $m a$ crocopa en relation avec la température, un suivi des paramètres liés à la fécondité a été réalisé (Fig. 6).

Les variations du nombre total moyen de jeunes par femelle, du nombre moyen de portées par femelle ainsi que du nombre moyen de jeunes par portée, mettent en évidence un accroissement particulièrement important de ces paramètres dans l'intervalle de température $15-20^{\circ} \mathrm{C}$. Au delà, les différences observées ne sont pas significatives. Entre 20 et $30^{\circ} \mathrm{C}$, le plafonnement à 70 du nombre total moyen de jeunes par femelle est à relier à la stabilité du nombre moyen de jeunes par portée $(12$ à 12,7$)$ qui s'accroît rapidement entre 15 et $20^{\circ} \mathrm{C}$. En revanche, le nombre de portées par femelle augmente sensiblement de 15 à $18^{\circ} \mathrm{C}$ mais bien plus lentement au dèlà.

La constance des 3 paramètres. de fécondité, dans l'intervalle de température $20-30^{\circ} \mathrm{C}$, n'est en fait qu'apparente. En effet, si l'on exprime les résultats en valeur relative, en tenant compte de la durée de vie reproductive à chaque température $\left(10,5\right.$ jours à $20^{\circ} \mathrm{C}$, 7,6 jours à $25^{\circ} \mathrm{C}$ et 6,1 jours à $30^{\circ} \mathrm{C}$ ), on constate en réalité que le nombre total moyen de jeunes par femelle, le nombre moyen de portées par femelle ainsi que le nombre de jeunes par portée, augmente sensiblement entre 20 et $30^{\circ} \mathrm{C}$. Cette augmentation est néanmoins compensée par la réduction de la période de maturité.

De même, nous avons constaté qu'à $15^{\circ} \mathrm{C}$, le maximum de jeunes est produit à la lère portée, alors qu'entre 18 et $20^{\circ} \mathrm{C}$, ce maximum apparaît à la seconde. Enfin, pour des températures d'élevage comprises entre 25 et $30^{\circ} \mathrm{C}$, la troisième portée correspond à la productivité maximale. Ces résultats sont en accord avec ceux obtenus chez d'autres espèces de Moina. L'augmentation de la température entraîne chez Moina micrura (Murugan 1975, Shehab \& Khalaf 1980) et Moina salina (Gordo \& Canavate 1989) une amélioration des processus de reproduction; les paramètres qui décrivent la fécondité atteignent en effet des valeurs optimales pour des températures relativement élevées (Tableau 5).

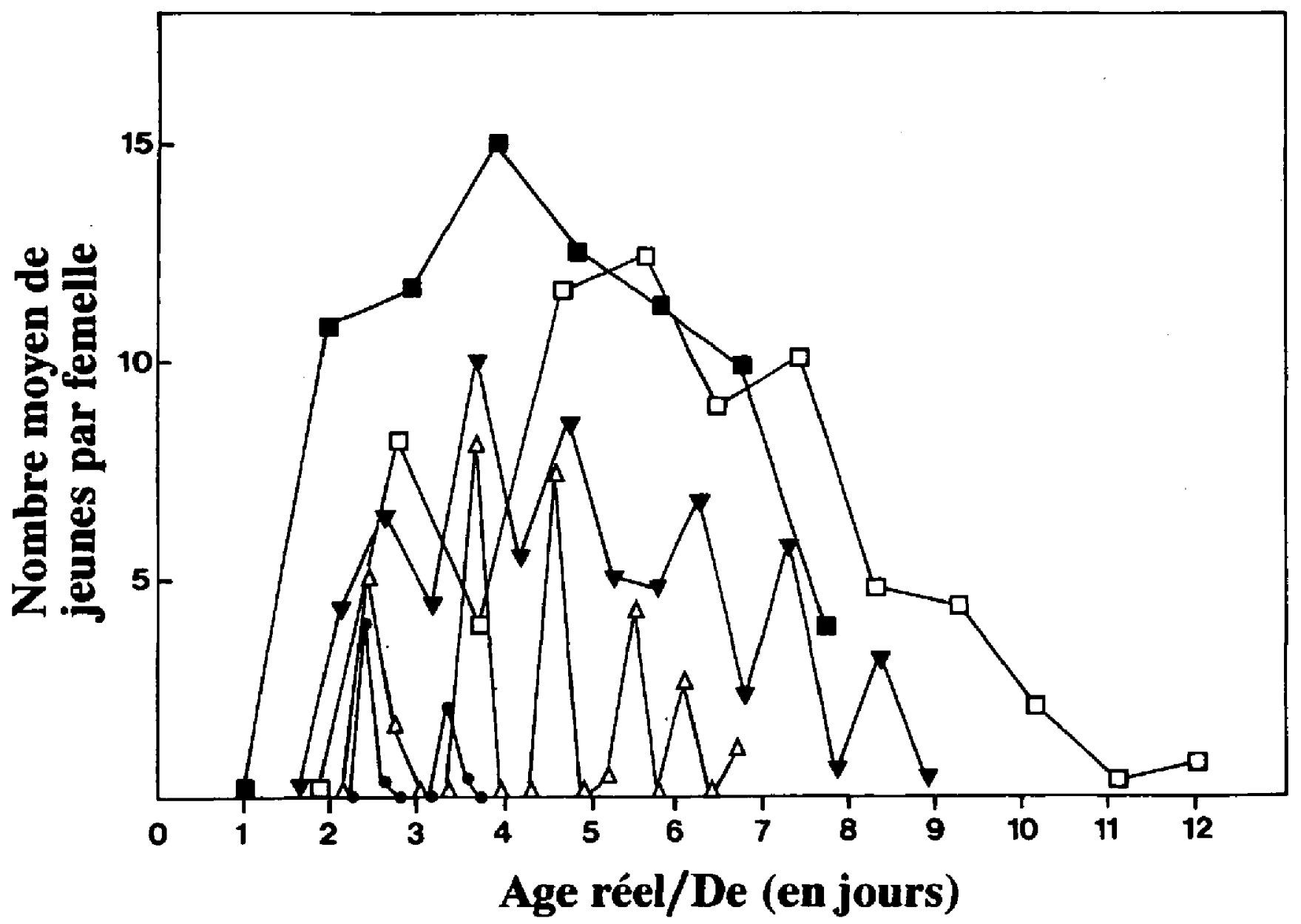

Figure 5. Courbes de fécondité en fonction de l'âge de la mère, à différentes températures (concentrations en algues : $6,25.10^{5}$ cellules/ml). $15^{\circ} \mathrm{C}(0) ; 18^{\circ} \mathrm{C}(\triangle) ; 20^{\circ} \mathrm{C}(\nabla) ; 25^{\circ} \mathrm{C}(\square) ; 30^{\circ} \mathrm{C}(\square)$.

Fig. 5. Fecundity curves according to the female age (algal concentration : $6,25.10^{5} \mathrm{cells} / \mathrm{ml}$ ). 


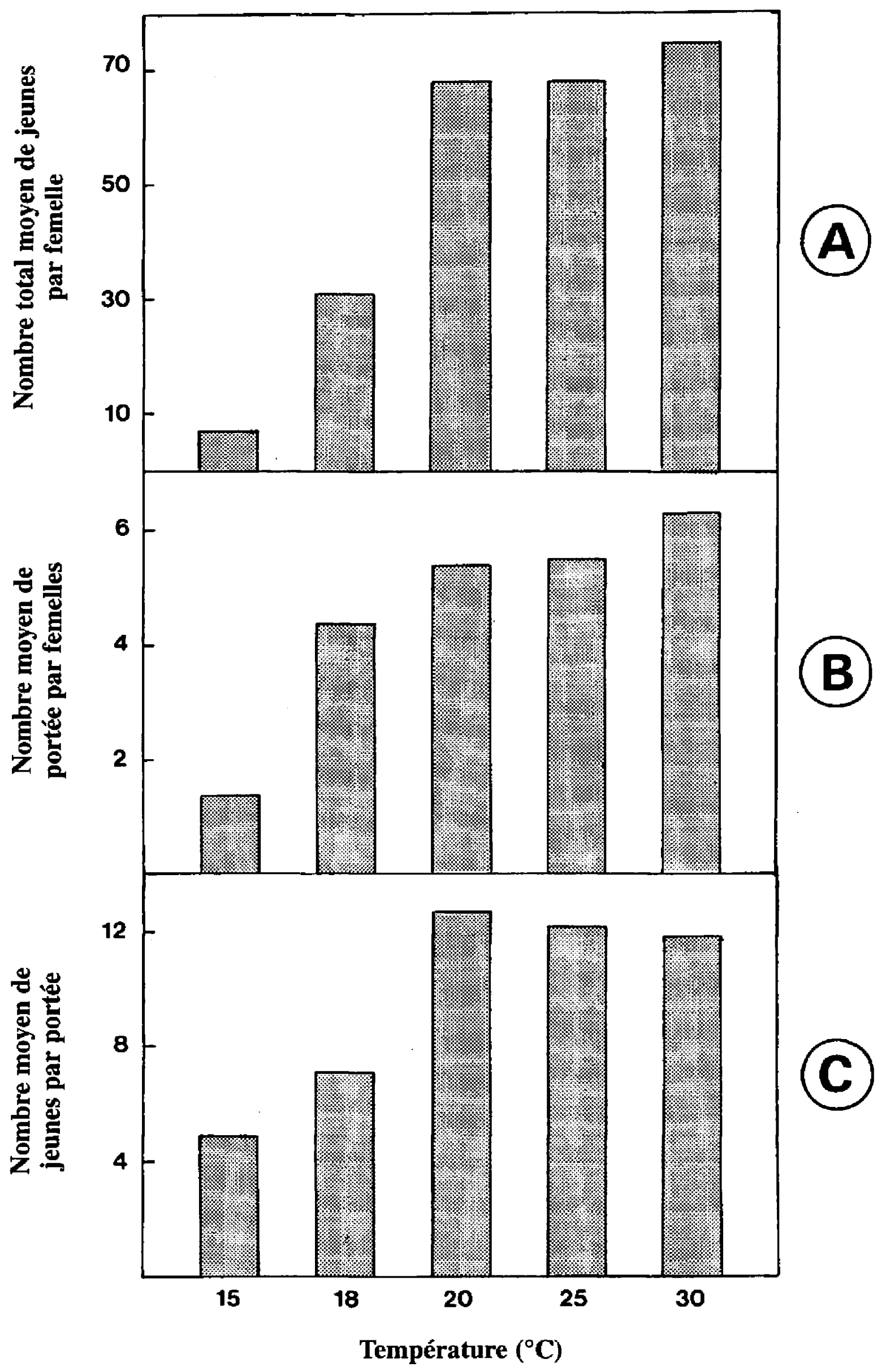

Fig.6. Nombre total moyen de jeunes par femelle (A), nombre moyen de portées par femelle (B) et nombre moyen de jeunes par portée (C) chez M. macrocopa, à 5 températures (concentrations en algues : $6,25 \cdot 10^{5}$ cell./ml).

Fig. 6. Total reproductive out put (A), brood number per female (B) and the average brood size (C) in Moina macrocopa, at 5 temperatures (algal concentration : $\left.6,25.10^{5} \mathrm{cells} / \mathrm{ml}\right)$. 


\section{Discussion et conclusion}

Les conditions de carence alimentaire sont une des principales causes de la réduction de la fécondité de $M$. macrocopa. Nous avons montré en effet qu'un apport insuffisant de nourriture (concentration en algues inférieure à $3,125.10^{4}$ cell. $/ \mathrm{ml}$ ) supprimait tout phénomène de reproduction. Les mêmes constations ont été faites par Lynch (1989) et Rothhaupt (1990).

- Au delà de cette notion de «niveau trophique seuil», l'utilisation de l'énergie fournie par la nourriture ingérée diffère selon l'importance des ressources du milieu et selon les espèces étudiées. En situation d'insuffisance alimentaire, cette énergie est investie exclusivement dans la survie des animaux (Lynch 1980); c'est le cas notamment de Moina macrocopa. En revanche, lorsqu'on dépasse le «niveau trophique seuil», la répartition de l'énergie entre la croissance et la reproduction dépend des espèces, observation faite par plusieurs auteurs (Snell \& King 1977, Lynch 1980, 1989, Threlkeld 1987, Duncan 1989). Ce type de stratégie conduit à une diminution de la longévité de ces espèces.

Chez Moina macrocopa, nous avons montré expérimentalement que l'augmentation de la densité de population entraînait une diminution de la fécondité des femelles, leur croissance corporelle n'étant pas affectée. Cet effet sur la fécondité, en raison des conditions expérimentales retenues, semble redevable uniquement de la réduction de l'espace de vie. Il est bien évi- dent qu'en milieu naturel, où les phénomènes de compétition nutritionnelle se superposent très souvent à la compétition spatiale, l'influence de la densité de population s'exerce à la fois sur les processus de croissance et de reproduction. Dans le présent travail, nous avons mis en évidence, par ailleurs, l'absence d'un effet du groupement sur la reproduction de Moina macrocopa.

Peu de travaux ont été jusqu'à présent consacrés à ces problèmes et les études réalisées, aussi bien chez les Cladocères (Jana \& Pal 1985a et b) que chez les Rotifères (Gilbert 1963, Clement \& Pourriot 1975, Pourriot \& Rougier 1977, Pourriot \& Clement 1981), soulignent la complexité de ces phénomènes et la difficulté d'interprétation des résultats obtenus.

L'influence de la température sur l'évolution des caractéristiques démographiques de Moina macrocopa permet de dégager les points suivants :

- les températures extrêmes létales correspondent à 10 et $35^{\circ} \mathrm{C}$. Ces limites diffèrent très nettement d'une espèce à l'autre et reflètent l'aptitude de chacune d'entre elles à se développer dans des milieux divers. Il est probable que l'adaptation aux températures élevées s'accompagne également d'une augmentation du «seuil inférieur réel de développement». La valeur de ce seuil est cependant difficile à estimer, en raison notamment du fait qu'il s'accompagne, dans les conditions artificielles, de fortes mortalités. Par ailleurs ce seuil correspond en général à l'apparition de la reproduction sexuée chez les Cladocères (Gras \& St-Jean 1976). Sa

Tableau 5. Fécondité et longévité de quelques espèces de Moinidae. (1): Hanazato \& Yasuno 1984 - (2) : présent travail - (3) : Shehab \& Khalef 1980 - (4) : Murugan 1975 - (5) : Lazim \& Faisal 1989 - (6) : Gordo \& Canavate 1989 - (7) : en gras et entre parenthèse : Gordo et al. 1994. NT J/F : Nombre total de jeunes par femelle ; N P/F : Nombre de portées par femelle ; N J/P : Nombre de jeunes par portée ; Dv : Durée de vie ; $\mathrm{T}$ : Température ; LD : Lumière-obscurité ; cell./ml : cellules par millilitre. S.sp. : Chlorella sp. ; C.s. : Chlorella sorokiniana ; L.g : Isochrysis galbana; C.c : Chaetoceros calcitraus.

Table 5. Fecundity and longevity of some Moinidae species.

\begin{tabular}{|c|c|c|c|c|c|c|c|c|}
\hline Espèces & NT J/F & N P/F & $\mathrm{N} \mathrm{J} / \mathrm{P}$ & Dv (j) & $\mathrm{T}\left({ }^{\circ} \mathrm{C}\right)$ & LD & Nourriture (cell./ml) & Références \\
\hline M. macrocopa & $\begin{array}{l}116 \\
7 \\
68 \\
68 \\
75\end{array}$ & $\begin{array}{l}5 \\
1,4 \\
5,5 \\
5,5 \\
6,3\end{array}$ & $\begin{array}{l}5 \\
12 \\
12 \\
12\end{array}$ & $\begin{array}{l}11 \\
15 \\
13 \\
9,5 \\
7,5\end{array}$ & $\begin{array}{l}23 \\
15 \\
20 \\
25 \\
30\end{array}$ & $\begin{array}{l}16: 8 \\
0: 24 \\
0: 24 \\
0: 24 \\
0: 24\end{array}$ & $\begin{array}{l}C . s p 1.10^{6} \\
C . s p 1.10^{5} \\
C . s p 1.10^{5} \\
C . s p 1.10^{5} \\
\text { C.sp } 1.10^{5}\end{array}$ & $\begin{array}{l}(1) \\
(2) \\
(2) \\
(2) \\
(2)\end{array}$ \\
\hline M. micrura & $\begin{array}{l}37 \\
61\end{array}$ & & 5,5 & $\begin{array}{l}20 \\
13\end{array}$ & $\begin{array}{l}20 \\
28-30\end{array}$ & & $\begin{array}{l}\text { phytoplancton } \\
\text { phytoplancton }\end{array}$ & $\begin{array}{l}(3) \\
(4)\end{array}$ \\
\hline M. brachiata & 83 & & 10,4 & 25 & 20 & & phytoplancton & (5) \\
\hline M. salina & $\begin{array}{l}(0,9) \\
(11,25) \\
(24,1) \\
(26,6)\end{array}$ & $\begin{array}{l}1,3-(2,3) \\
2,3-(2,65) \\
2,9-(4,05) \\
4,2-(5,45)\end{array}$ & $\begin{array}{l}0,3-(0,43) \\
3,9-(4,74) \\
5,5-(\mathbf{5 , 8 5}) \\
4,2-(\mathbf{5 , 1 5})\end{array}$ & $\begin{array}{l}(27,15) \\
(22,75) \\
(15,45) \\
(10,9)\end{array}$ & $\begin{array}{l}15 \\
20 \\
25 \\
30\end{array}$ & & $\begin{array}{l}\text { I.g et C.c }\left(1-1,5,10^{5}\right) \\
\text { I.g et C.c }\left(1-1,5.10^{5}\right) \\
\text { I.g et C.c }\left(1-1,5.10^{5}\right) \\
\text { l.g et C.c }\left(1-1,5.10^{5}\right)\end{array}$ & $\begin{array}{l}\text { (6) et (7) } \\
(6) \text { et }(7) \\
(6) \text { et }(7) \\
(6) \text { et }(7)\end{array}$ \\
\hline
\end{tabular}


signification est donc discutable. Vijverberg (1980) situe sa valeur vers $2,5^{\circ} \mathrm{C}$ pour Daphnia hyalina, Daphnia cucullata, Bosmina longirostris, Bosmina coregoni et Chydorus sphaericus, Hall (1964) vers $4^{\circ} \mathrm{C}$ chez Daphnia galeata mendotae, Herzig (1984) vers $4,5^{\circ} \mathrm{C}$ chez Diaphanosoma brachyurum, mais elle est plus élevée, selon Vijverberg (1980), chez Ceriodaphnia pulchella et Leptodora kindtii $\left(>10^{\circ} \mathrm{C}\right)$.

- les durées de développement embryonnaire, postembryonnaire ainsi que le temps minimum de génération sont d'autant plus courts que la température du milieu est élevée. Ce type de réponse semble être généralisable à l'ensemble des Cladocères (Botrell 1975a et b, Munro \& White 1975, Gras \& St-Jean 1976, 1978b, de Bernardi et al. 1978, Herzig 1984, Hanazato \& Yasuno 1985), aux Rotifères (Pourriot \& Deluzarches 1971) et aux Copépodes (Botrell 1975a, Gras \& St-jean 1976). En effet, les valeurs mentionnées par ces auteurs ne diffèrent que légèrement. Ainsi, Gras \& St-Jean (1976) ont observé des valeurs de 0,96 et 1,26 jours, Hart (1985) 0,88 et 1,17 jours, Bonou et al. (1991), 0,82 et 1,22 jours pour Moina micrura. Par ailleurs, bien que mineures, ces différences sont probablement significatives et pourraient être expliquées par plusieurs facteurs dont les conditions de nutrition des femelles dans la mesure où celles-ci fournissent à l'embryon une grande partie des substances nécessaires à son développement. La fécondité globale s'accroît de manière considérable avec la température et se stabilise à partir de $20^{\circ} \mathrm{C}$. Quoique plus importante par rapport aux autres espèces du même genre, la production de jeunes chez Moina macrocopa est nettement inférieure à celle des Daphnies (Murugan \& Sivarmakkrishnan 1973).

Au terme de ce travail, nous pouvons conclure que la connaissance des caractéristiques démographiques de Moina macrocopa constitue un apport important dans l'objectif de l'étude de la compétition avec Daphnia magna. Les données de la littérature font état d'une durée de vie potentielle, 45 jours en moyenne à $20^{\circ} \mathrm{C}$ (Lynch 1980) et d'une fécondité globale, 832 jeunes/femelle, à $14-18^{\circ} \mathrm{C}$. Chez Daphnia magna (Green 1953), elle est plus importante. Par comparaison à celui de Daphnia magna $(\mathrm{De}=70$ heures et $\mathrm{Dp}=$ 132 heures, à $22^{\circ} \mathrm{C}$, avec des Chlorelles comme nourriture, Green 1956; $\mathrm{De}=84$ heures et $\mathrm{Dp}=144$ heures, à $18-20^{\circ} \mathrm{C}$, Zaffagnini 1964) on peut supposer que la première espèce, M.macrocopa pourrait être plus compétitive. En réalité, les phénomènes de compétition sont beaucoup plus complexes et intègrent d'autres facteurs tels que l'âge des compétiteurs et le niveau des ressources disponibles (Smith \& Cooper 1982, Till- mann \& Lampert 1984). Ainsi, d'après les observations de plusieurs auteurs (Gras \& St-Jean 1976 , D'Abramo 1980, Myrand \& De La Noue 1982, Vijverberg \& Richter 1982, Bonou et al. 1991, Tifnouti et al. 1993, Gordo et al. 1994), l'extension de la comparaison à d'autres espèces montre que $M$. macrocopa, sinon le genre Moina, se différencie de la plupart des autres Cladocères par un développement juvénile plus court, qui peut approcher la durée de développement embryonnaire et post-embryonnaire.

\section{Remerciements}

Les auteurs remercient Mme C. Rougier, MM. G. Lacroix et P. Testard pour la lecture du manuscrit, leurs critiques constructives et leur aide apportée dans sa réalisation.

Travail réalisé dans le cadre du projet CEE. Programme SEM $\mathbf{n}^{\circ}$ 03/204/017. «Soutien à la recherche Scientifique au Maroc» Convention de financement $n^{\circ} 177 / \mathrm{MAR}$.

\section{Travaux cités}

Angeli N. 1979. - Relations entre le plancton et la qualité de l'eau. Thèse de Doctorat d'Etat Université de Lille : $280 \mathrm{p}$.

Benider A. 1991. - Caractères démographiques de Moina macrocopa (Cladocera : Moinidae) en élevage au laboratoire. Influence des conditions trophiques, de la densité de population, du groupement et de la temperature. Thèse de Doctorat de $3^{\text {àme }}$ cycle, Univ. Cadi Ayyad, Marrakech : 75 p.

Bonou C.A. 1990. - Etude de la productivité planctonique dans des étangs d'aquaculture en milieu saumâtre tropical. Thèse de Doctorat, I.N.P. de Toulouse : $220 \mathrm{p}$.

Bonou C.A., Pagano M. \& Saint-Jean L.1991. - Développemant et croissance en poids de Moina micrura et de Mesocyclops aginnus dans un milieu saum, tre tropical : les étangs de pisciculture de Layo (Côte d'Ivoire). Rev. Hydrobiol. trop. 24 : 287-303

Botrell H.H. 1975a. - The relation between temperature and duration of egg development in some epiphytic Cladocera and Copepoda from the River Thames, Reading, with a discussion of temperature functions. Oecologia : $18: 63-84$.

Botrell, H. H. 1975 b. - Generation time, length of life, instar duration and frequency of moulting, and their relationship to temperature in eight species of Cladocera from the River Thames, Reading. Oecologia, $19: 129-140$.

Brown L.A. 1929. - The natural history of Cladocera in relation to temperature. Distribution and the temperature limits for vital activities. Am. Nat., $63: 248-264$.

Chifâa A. 1987. - Phytoplancton des bassins de lagunage de Marrakech. Thèse de Doctorat de $3^{\text {zeme }}$ cycle, Univ. Cadi Ayyad, Marrakech : $173 \mathrm{p}$

Clement P. \& Pourriot R. 1975. - - Influences du groupement et de la densité de population sur le cycle de reproduction de Notommata copeus (Rotifere). I. Arch. Zool. exp. gén., $116: 375-422$.

Conklin D.E. \& Provasoli L. 1977. - Nutritional requirements of the water flea Moina macrocopa. Biol. Bull., $152: 337-350$.

D'Abramo L.R. 1980. - Ingestion rate decrease as the stimulis for sexuality in populations of Moina macrocapa. Limnol. Oceanogr., 25 (3) : 422-429.

de Bernardi R., Lacqua P. \& Soldavini E. 1978. - Effects of temperature and food on developmental times and growth in Daphnia obtusa (Kurz) and Simocephalus vetulus (O.F. Müller) (Crustacea, Cladocera). Mem. Ist. Ital. Idrobiol., 36 : 171-191. 
Dinges W.R. 1973. - Ecology of Daphnia in stabilization ponds. Texas Dep. Health Ressources, Div. Wastewater Technol. Surveillance, $\mathrm{LX}: 155 \mathrm{p}$.

Duncan A. 1989. - Food limitation and body size in the life cycles of planktonic rotifers and cladocerans. Hydrobiologia, 186/187 : 11-28.

Gauthier H. 1954. - Essai sur la variabilité, l'écologie, le déterminisme du sexe et la reproduction de quelques Moina (Cladocères) récoltées en Afrique et à Madagascar. Minerva, Alger : 248 p.

Gilbert J.J. 1963. - Mictic female production in the rotifer Brachionus calyciflonus. J. Exp. Zool., 153 (2) : 113-124.

Gordo T. \& Canavate J.P. 1989. - The development and reproduction of Moina salina (Crustacea : Cladocera). European Aquaculture Society. EAS Special Publication $n^{\circ} 10$.

Gordo T., Lubian L.M. \& Canavate J.P 1994. - Infuence of temperature on growth, reproduction and longevity of Moina salina Daday, 1888 (Cladocera, Moinidae). J. Plankton Res. 16 (11) : 1513 1523.

Goulden C.E. 1968. - The systematics and evolution of the Moinidae. Trans. Amer. Phil. Soc., 58 (6) : 101 p.

Gras R. \& Saint-Jean L. 1976. - Durée du développement embryonnaire chez quelques espèces de Cladocères et de Copepodes du lac Tchad. Cah. O.R.S.T.O.M., sér. Hydrobiol., 10 (4) : 233254.

Gras R. \& Saint-Jean L. 1978a. - Taux de natalité et relation entre les paramètres d'accroissement et d'abondance dans une population à structure $d^{\prime}$, ge stable : cas d'une population de Cladocères à reproduction par parthénogénèse. Cah. O.R.S.T.O.M., sér. Hydrobiol., 12 (1) : 19-63.

Gras R. \& Saint-Jean L. 1978b. - Durée et caractérisques du développement juvénile de quelques Cladocères du lac Tchad. Cah. O.R.S.T.O.M., sér. Hydrobiol., 12 (2) : 119-136.

Green J. 1953. - Size and reproduction in Daphnia magna (Crustacea : Cladocera). Proc. Zool. Soc. Lond., 124 : 535-545.

Green J. 1956. - Growth, size and reproduction in Daphnia (Crustacea : Cladocera). Proc. Zool. Soc. Lond,, 126: 173-204.

Hall D.J. 1964. - An experimental approch to the dynamics of a natural population of Daphnia galeata mendotae. Ecology, 45 (1) : 94-112.

Hanazato T. \& Yasuno M. 1984. - Growth, reproduction and assimilation of Moina macrocopa fed on Microcystis and/or Chlorella. Jap. J. Ecol., 34 (2) : 195-202.

Hanazato T. \& Yasuno M. 1985. - Effect of temperature in the laboratory studies on growth, egg development and first parturition of five species of Cladocera. Jap. J. Limnol., 46 (3) : 185-191.

Hart R.C. 1985. - Embryonic development times of entomostracan zooplankton from lake Le Roux (Orange River, South Africa) and their possible relationships to seasonal succession. Hydrobiologia, $127: 17-26$.

Herzig A. 1984. - Temperature and life cycle strategies of Diaphanosoma brachyurum : an experimental study on development, growth, and survival. Arch. Hydrobiol., 101 (1/2) : 143-178.

Jana B.B. \& Pal G.P. 1985a. - The life history parameters of Moina micrura (Kurz) grown in different culturing media. Water Res., $19(7): 863-867$

Jana B.B. \& Pal G.P. 1985b. - Effects of inoculum density on growth, reproductive potential and population size in Moina micrura (Kurz). Limnologica, 16 (2) : 315-324.

Krebs C.J. 1978. - Ecology : the experimental analysis of distribution and abundance. Harper and Row, New York : 687 p.
Lazim M.N. \& Faisal M.Z. 1989. — Laboratory studies on the longevity, instar duration, growth, and reproduction in Moina rectirostris (Leydig) (Cladocera : Moinidae). J. Biol. Sci. Res., 20 (3) : 419-428.

Loedolff C.J. 1965. - The function of Cladocera in oxydation ponds. Proc. 2d Int. Wat. Poll. Res. Conf., Tokyo : 307-325.

Lynch M. 1980. - The evolution of Cladoceran life histories. The Quarterly Review of Biology, $55: 23-42$.

Lynch M. 1989. - The life history consequences of resource depression in Daphnia pulex. Ecology, $700: 1246-256$.

Magadza C.H.D. 1977. - Determination of development period at various temperatures in a tropical Cladoceran, Moina dubia de Guerne and Richard. Trans. Rhod. Scient. Ass., 58 (4) : 24-27.

Mangalo H.H. \& Akbar M.M. 1986. - Size and reproduction in natural population of Moina affinis (Cladocera - Crustacea) in Diyala River at Baghdad, Iraq. J. Biol. Sci. Res., 17 (3) : 85-97.

Manning J.T. \& Jenkins J. 1980. - The «Balance» argument and evolution of sex. J. theor. Biol., 86:593-601.

Montu M. 1973a. - Crecimiento y desarollo en algunas especies de cladocero dulceacuicolas. П. Moina micrura (Kurz, 1874). Physis (B), 32: 93-104.

Montu M. 1973b. - Crecimiento y desarollo en algunas especies de cladocero dulceacuicolas. II. Moina reticulata (Daday, 1905). Physis (B), 32 : 207-214.

Munro I.G. \& White R.W.G. 1975. - Comparaison of the influence of temperature on the egg development and growth of Daphnia longispina O.G. Müller (Crustacea : Cladocera) from two habitats in Southem England. Oecologia, 20 : 157-165.

Murugan N.'\& Sivaramakrishan K.G. 1973. - The biology of Simocephalus acutirostratus King (Cladocera : Daphnidae)-laboratory studies of life span, instar duration, egg production, growth and stages in embryonic development. Freshwat. Biol., $3: 77-83$.

Murugan N. 1975. - Egg production, development and growth in Moina micrura Kurz (1874) (Cladocera : Moinidae). Freshwat. Biol., 5 : 245-250.

Myrand B. \& de la Noue J. 1982. - Croissance individuelle et dynamique de population de Daphnia magna en culture dans les eaux usées traitées. Hydrobiologia, $97: 167-177$.

Pizay-Parenty M.D. 1985. - Bassins de lagunage d'Aniche-Auberchicourt (Nord) : cinétiques saisonnières et spatiales du zooplancton et des descripteurs de la qualité de l'eau. Thèse de Doctorat

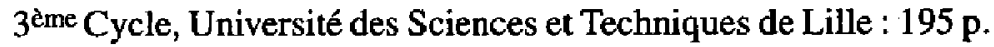

Pourriot R. \& Clement P. 1981. - Action de facteurs externes sur la reproduction et le cycle reproducteur des rotifères. Acta OEcologica OEcol., Gener., 2 (2) : 135-151.

Pourriot R. \& Deluzarches M. 1971. - Recherches sur la biologie des Rotifères. II. Influence de la température sur la durée du développement embryonnaire et post-embryonnaire. Annls Limnol., 7 (1) : 25-52.

Pourriot R. \& Rougier C. 1976. - Influence de l'âge des parents sur la production de femelles mictiques chez Brachionus calyciflorus (Pallas) et Brachionus rubens Ehr. (Rotifères). C. R. Acad. Sc. Paris, 283, Série D : 1497-1500.

Pourriot R. \& Rougier C. 1977. - Effets de la densité de population et du groupement sur la reproduction de Brachionus calyciflorus Pallas (Rotifère). Annls Limnol., 13 (2) : 101-113.

Ricklefs R.E. 1973. - Ecology. Chiron Press, Portland, 861 p.

Shehab A.F. \& Khalaf A.N. 1980. - The effect of temperature on the growth, and reproduction of Moina micrura Kurz (Crustacea : Cladocera). Bull. Biol. Res. Cent., 12/2 : 49-73. 
Smith D.W. \& Cooper S.D. 1982. - Competition among Cladocera. Ecology, 63(4) : 1004-1015.

Snell T.W. \& King C.E. 1977. - Lifespan and fecundity patterns in Rotifers : the cost of reproduction. Evolution, $31: 882-890$.

Taylor B. E. 1985. - Effects of food limitation on growth and reproduction of Daphnia. Arch. Hydrobiol. Beih. 21 : 285-296.

Threlkeld S.T. 1987. - Daphnia life history strategies and resource allocation pattems. In «Daphnia». R.H. Peters and R, de Bernardi (Eds.). Mem. Ist. Ital. Idrobiol., 45 : 353-366.

Tifnouti A. \& Pourriot R. 1989. - Dynamique d'une population de Moina micrura (Crustacea, Cladocera) dans un bassin de lagunage à Marrakech (Maroc). Rev. Hydrobiol. trop., 22 (3) : 239-250.

Tifnouti A 1987. - Zooplancton des bassins de lagunage de Marrakech. Structure du peuplement et dynamique des principales populations. Thèse de Doctorat $33^{\text {ème }}$ Cycle,Université Cadi Ayyad, Marrakech, 198 p.

Tillmann U. \& Lampert W. 1984. - Competitive ability of differently sized Daphnia species : an experimental test. J. Freshwat. Ecol., 2 (4) : 311-323.
Van Dehn M. 1955. - Die Gechlechtsbestimmung der Daphnidien. Die Bedeutung der Fettstoffe, untersucht an Moina rectirostris. L. Zool. Jahrb., 65 : 334-356.

Vijverberg J. \& Richter A. F. 1982. - Population dynamics and production of Daphnia hyalina leydig and Daphnia cucculata in Tjeukemeer. The Neetherlands. Thèse, Rijkuniversiteit te Leiden : 95-146.

Vijverberg J. 1976. - The effect of food quantity and quality on growth, birth-rate and longevity of Daphnia hyalina Leydig. $H y-$ drobiologia, 51 : 99-108.

Vijverberg J. 1980. - Effect of temperature in laboratory studies on development and growth of Cladocera and Copepoda from Tjeukemeer, The Netherlands. Freshwater Biol, 10 (4) : 317-340.

Weglenska T. 1971. - The influence of various concentrations of natural food on the development, fecundity and production of planktonic Crustacean filtrators. Ekol. Pols., 19 (30) : 427-471.

Zaffagnini F., 1964. - Osservazioni comparative sull accrescimento e la riproduzione in tre specie di Cladoceri. Mem. Ist. ital. Idrobiol., $17: 103-114$ 